\title{
The Efficiency Optimization of Permanent Magnet Synchronous Machine DTC for Electric Vehicles Applications Based on Loss Model
}

\author{
Like Zhao ${ }^{1}$, Xiaomin Zhou ${ }^{1}$, Dawei Gao ${ }^{2}$ \\ 1 School of Mechanical Engineering, University of Science and Technology Beijing, Beijing, \\ 100083, China \\ 2 State Key Laboratory of Automotive Safety and Energy Tsinghua University, Beijing, 100084, \\ China
}

Keywords: Permanent Magnet Synchronous Machine, Direct Torque Control, Loss Model, Iron Loss Resistance, Efficiency Optimization.

\begin{abstract}
An efficiency optimization method of permanent magnet synchronous machine for electric vehicles applications is researched. Considering iron loss equivalent resistance and direct torque control scheme, the relationship of stator flux and power loss is derived based on loss model. And then the real-time optimal target flux can be obtained through the relationship of d-axis stator flux, target torque and electric speed at the minimum loss situation. A fitting curve of iron loss equivalent resistance versus speed is obtained by simulation. This makes the iron loss equivalent resistance closer to the actual value compared with the fixed value. Simulation results show that the motor efficiency has been improved compared with traditional direct torque control.
\end{abstract}

\section{Introduction}

Compared with conventional internal combustion engine vehicles, the electric vehicles are cleaner, more efficiency and lower noise. It is currently the most promising development direction of the automotive industry with better dynamic performance [1]. The permanent magnet synchronous motor (PMSM) with small size, light weight, compact structure, highly efficiency is suitable as electric vehicle drive motor. Variable Voltage and Variable Frequency (VVVF), Vector Control (VC), Direct Torque Control (DTC) are the three methods for permanent magnet synchronous motor control [2]. Direct Torque Control (DTC) has advantages of simple control structure, fast torque response and robustness. Although permanent magnet synchronous motors have higher efficiency compared with asynchronous motors, the loss of the motor is still exist.

Wang Jin [3] analyzed factors affecting motor's losses and also concluded methods decreasing losses. Xu Jun-feng [4] and Xu Yan-ping [5] studied the relationship of current and loss of surface permanent magnet synchronous motor. Chen $\mathrm{Xu}$ [6] proposed LMC (loss minimum control) based on searching method. Kang Chang [7] presented a generalized relationship between d-q current for the LMC of PMSM. It showed that maximum torque per ampere and maximum torque per voltage can be derived as special case of LMC. The d-q current was treated as direct control value in this method. A. Dittrich [8] and Naomitsu Urasaki etc. [9] proposed a calculation method for iron loss resistance in the offline manner based on the linear feature between semi-input power and square of speed electromotive force.

The loss of motors includes iron loss, copper loss, stray loss and mechanical loss [10]. The mechanical loss can't be controlled as it is not directly related to current, torque and flux values. Just iron loss and copper loss are described in this paper.

\section{The loss model of PMSM}

The d-q axis equivalent circuit of PMSM considering iron loss and copper loss is shown in Figure 1. For control purpose, the iron loss is modelled as a resistance, known as iron loss resistance which is in parallel in the circuit. The d-q axis current is divided into iron loss current and excitation current. 


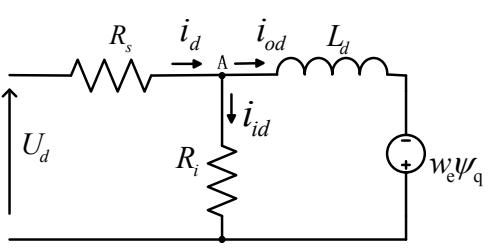

(a) The equivalent circuit of $d$-axis

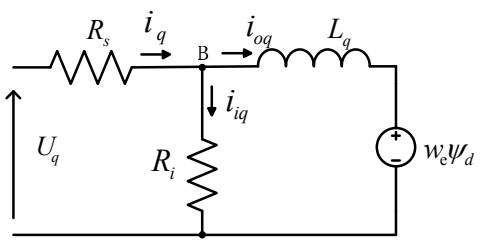

(b) the equivalent circuit of q-axis

Figure 1 the equivalent circuit

The d-q axis flux and the electromagnetic torque are calculated as the formula (1), (2), (3) shown.

$$
\begin{gathered}
\psi_{d}=L_{d} i_{o d}+\psi_{f} \\
\psi_{q}=L_{q} i_{o q} \\
T_{e}=1.5 n_{p}\left(\psi_{f} i_{o q}+\left(L_{d}-L_{q}\right) i_{o d} i_{o q}\right)
\end{gathered}
$$

where $\psi_{\mathrm{d}}$ is the $\mathrm{d}$ axis flux, $\psi_{\mathrm{q}}$ is $\mathrm{q}$ axis flux, $\mathrm{L}_{\mathrm{d}}$ is the $\mathrm{d}$ axis inductance, $\mathrm{L}_{\mathrm{q}}$ is the $\mathrm{q}$ axis inductance, $\psi_{\mathrm{f}}$ is the rotor flux, $\mathrm{i}_{\text {od }}$ is the $\mathrm{d}$ axis excitation current, $\mathrm{i}_{\mathrm{oq}}$ is the $\mathrm{q}$ axis excitation current, $\mathrm{n}_{\mathrm{p}}$ is the pole pairs, $\mathrm{T}_{\mathrm{e}}$ is the electromagnetic torque.

According to the formula (1), (2), the excitation currents can be calculated as the formula (4), (5) shown.

$$
\begin{gathered}
i_{o d}=\frac{\psi_{d}-\psi_{f}}{L_{d}} \\
i_{o q}=\frac{\psi_{q}}{L_{q}}
\end{gathered}
$$

The $i_{d}, i_{q}$ can be calculated as formula (6), (7) shown by applying the Kirchhoff's first law for node $\mathrm{A}, \mathrm{B}$ in Figure 1.

$$
\begin{aligned}
& i_{d}=i_{o d}+i_{i d} \\
& i_{q}=i_{o q}+i_{i q}
\end{aligned}
$$

Where $i_{d}$ is the $d$ axis current, $i_{q}$ is the $q$ axis current, $i_{i d}$ is the $d$ axis iron loss current, $i_{i q}$ is the $q$ axis iron loss current.

The formula (8), (9) can be obtained by applying the Kirchhoff's second law to the right side loop in the Figure 1.

$$
\begin{gathered}
p L_{d} i_{o d}-\omega_{e} L_{q} i_{o q}-R_{i} i_{i d}=0 \\
p L_{q} i_{o q}+\omega_{e}\left(L_{d} i_{o d}+\psi_{f}\right)-R_{i} i_{i q}=0
\end{gathered}
$$

Where $\mathrm{p}$ is the differential operator, $\omega_{\mathrm{e}}$ is the electric speed, $\mathrm{R}_{\mathrm{i}}$ is the iron loss resistance.

In the steady state, $p=0$. The steady-state iron loss current expression is shown as formula (10), (11).

$$
\begin{gathered}
i_{i d}=\frac{-\omega_{e} L_{q} i_{o q}}{R_{i}} \\
i_{i q}=\frac{\omega_{e}\left(L_{d} i_{o d}-\psi_{f}\right)}{R_{i}}
\end{gathered}
$$

The iron loss $\mathrm{P}_{\text {iron }}$ and copper loss $\mathrm{P}_{\mathrm{cu}}$ are computed shown as formula (12), (13).

$$
\begin{gathered}
P_{\text {iron }}=1.5 R_{i}\left(i_{i d}^{2}+i_{i q}^{2}\right)=\frac{1.5 \omega_{e}^{2}\left(L_{q} i_{o q}\right)^{2}}{R_{i}}+\frac{1.5 \omega_{e}^{2}\left(\psi_{f}+L_{d} i_{o d}\right)^{2}}{R_{i}} \\
P_{c u}=1.5 R_{s}\left(i_{d}^{2}+i_{q}^{2}\right)=1.5 R_{s}\left(\left(i_{o d}-\frac{\omega_{e} L_{q} i_{o q}}{R_{i}}\right)^{2}+\left(i_{o q}+\frac{\omega_{e}\left(L_{d} i_{o d}+\psi_{f}\right)}{R_{i}}\right)^{2}\right)
\end{gathered}
$$

The final power losses including both copper loss and iron losses can be represented as formula (14).

$$
P_{\text {loss }}=P_{\text {iron }}+P_{c u}
$$


According to the formula (4), (5), (12), (13), (14), formula (15) can be obtained.

$$
P_{\text {loss }}=a \psi_{d}^{2}+b \psi_{q}^{2}+c \psi_{d} \psi_{q}+d \psi_{d}+e \psi_{q}+f
$$

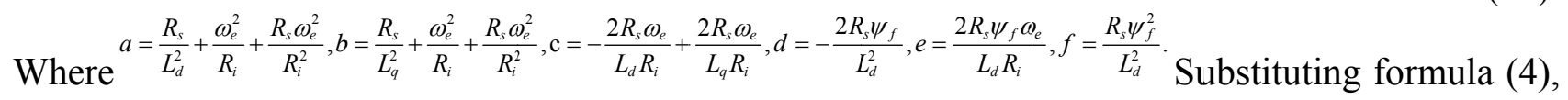
(5) into (3), the relationship of $\mathrm{T}_{\mathrm{e}}$ and $\psi_{\mathrm{q}}$ is obtained as formula (16).

$$
\psi_{q}=\frac{2 T_{e} L_{d} L_{q}}{3 n_{p}\left(L_{d} \psi_{f}+\left(\psi_{d}-\psi_{f}\right)\left(L_{d}-L_{q}\right)\right)}
$$

The relationship of $\mathrm{P}_{\text {loss }}$ and $\Psi_{\mathrm{d}}$ including unknown quantity $\Psi_{\mathrm{d}}, \mathrm{T}_{\mathrm{e}}, \omega_{\mathrm{e}}$ can be obtained by substituting formula (16) into formula (15). In the steady state, $\mathrm{T}_{\mathrm{e}}, \omega_{\mathrm{e}}$ are constant values. So, the power loss $P_{\text {loss }}$ is only related to $\Psi_{\mathrm{d}}$. The flux corresponding to the minimum loss of this torque value can be obtained by derivation the power losses $P_{\text {loss }}$ with respect to $\Psi_{d}$ as shown in formula 17 .

$$
\frac{\partial P_{\text {loss }}}{\partial \psi_{d}}=0
$$

Formula (17) can be rewritten as formula (18).

$$
a_{4} \psi_{d}^{4}+a_{3} \psi_{d}^{3}+a_{2} \psi_{d}^{2}+a_{1} \psi_{d}+a_{0}=0
$$

Also the factor expressions are as: $a_{4}=2 a u^{3}, a_{3}=6 a u^{2} z+d u^{3}$,

$a_{2}=6 a u z^{2}+3 d u^{2} z, a_{1}=2 a z^{3}+c k u z+3 d z^{2} u-e k u^{2}, a_{0}=c k z^{2}+d z^{3}-2 b k^{2} u-u e k z$,

$k=2 T_{e} L_{d} L_{q}, u=3 n_{p}\left(\mathrm{~L}_{d}-\mathrm{L}_{q}\right), \mathrm{z}=3 n_{p} L_{q} \psi_{f}$.

According to the formula (18), the optimal $\mathrm{d}$ axis flux value can be obtained. The target $\mathrm{q}$ axis flux value can be obtained by substituting the target $d$ axis flux value into equation (16). The stator target flux value corresponding to the minimum loss can be obtained shown as the equation (19).

$$
\psi^{*}=\sqrt{\left(\psi_{d}^{2}+\psi_{q}^{2}\right)}
$$

\section{The estimate of equivalent iron loss resistance}

Loss resistance in minimum loss iron model is a changing value. There are different ways to estimate the resistance off-line. This paper estimates the iron loss resistance by finite element analysis. Motor finite element model is shown in Figure 2. Dimensions of the model are listed in Table 1.

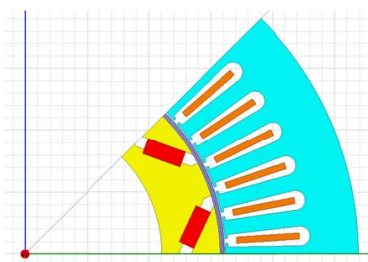

Figure 2 Motor finite element model

Table 1 Dimensions of the motor

\begin{tabular}{ll}
\hline name & \multicolumn{1}{c}{ value } \\
\hline DiaGap of Stator & $161.9(\mathrm{~mm})$ \\
\hline DiaYoke of Stator & $269.24(\mathrm{~mm})$ \\
\hline DiaGap of Rotor & $160.4(\mathrm{~mm})$ \\
\hline DiaYoke of Rotor & $110.64(\mathrm{~mm})$ \\
\hline Slots & 48 \\
\hline
\end{tabular}

The input power can be expressed as formula (20).

$$
P_{i n}=U_{d} i_{d}+U_{q} i_{q}=R_{s}\left(i_{d}^{2}+i_{q}^{2}\right)+\frac{\omega_{e}^{2}\left(\psi_{d}^{2}+\psi_{q}^{2}\right)}{R_{i}}+\omega_{e}\left(\psi_{d} i_{o q}-\psi_{q} i_{o d}\right)
$$


Where the first term is the copper loss, the second term is the iron loss, and the third term is the output power. The Electromotive Force (EMF) is proportional to the square of the iron loss and the ratio is the inverse of the iron loss equivalent resistance. The simulation parameters of the motor are listed in Table 2.

Table 2 The motor parameters used in the simulation

\begin{tabular}{ll}
\hline Stator resistance $(\Omega)$ & 0.069 \\
\hline d axis inductance $(\mathrm{H})$ & 0.002 \\
\hline $\mathrm{q}$ axis inductance $(\mathrm{H})$ & 0.006 \\
\hline Rotor flux $(\mathrm{Vs})$ & 0.158 \\
\hline Pole pairs & 4 \\
\hline
\end{tabular}

By changing the d-axis current at the speed of $837.758 \mathrm{rad} / \mathrm{s}$, a set of iron loss is recorded shown in Table 3. Changing the d-axis current only affects the d-axis flux. The fitting curve shown in Figure 3 is acquired by using a linear fitting algorithm. The slope of the curve is the equivalent iron loss resistance at this speed.

Table 3 A set of iron loss at the electric speed of $837.758 \mathrm{rad} / \mathrm{s}$

\begin{tabular}{ll}
\hline$\omega_{\mathrm{e}}^{2} \psi_{\mathrm{s}}^{2}(\mathrm{~V} 2)$ & Piron $(\mathrm{w})$ \\
\hline 22237.05 & 61.1584 \\
27514.88 & 74.5987 \\
33354.1 & 90.9784 \\
39754.94 & 104.1844 \\
46717.18 & 121.8611 \\
54240.89 & 139.7776 \\
62326.07 & 157.0671 \\
70972.72 & 174.5733 \\
80180.84 & 191.8711 \\
\hline
\end{tabular}

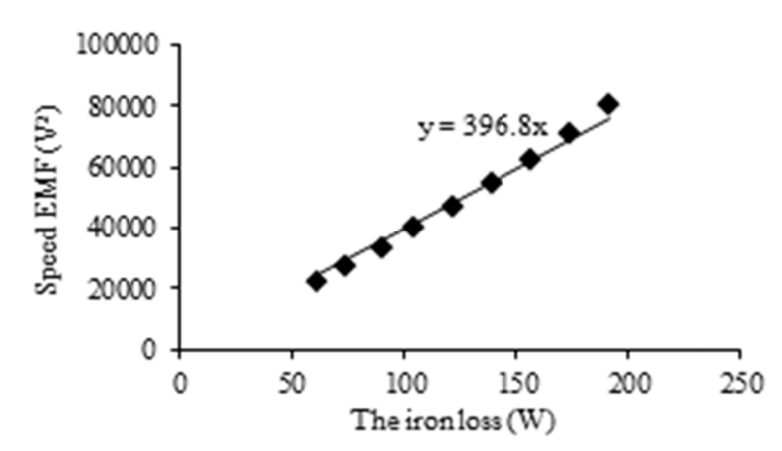

Figure 3 The fitting curve of iron power loss and EMF at $837.758 \mathrm{rad} / \mathrm{s}$

In the same manner, the iron loss resistance at other speeds can be obtained shown in Table 4. It can be seen that the iron loss resistance increases with speed increasing.

Table 4 The iron loss resistance at different speed

\begin{tabular}{|c|c|c|}
\hline Speed $[\mathrm{rad} / \mathrm{s}]$ & $\begin{array}{l}\text { Iron } \\
\text { resistance }[\Omega]\end{array}$ & loss \\
\hline 418.879 & 235.1 & \\
\hline 628.3185 & 320.7 & \\
\hline 837.758 & 396.8 & \\
\hline 1047.198 & 456.4907 & \\
\hline 1256.637 & 512.5 & \\
\hline
\end{tabular}


The fitting curve is shown in Figure 4. The regression coefficient of the fitting curve is 0.991 which means that the formula well describes the trend of iron loss resistance. The iron loss resistance satisfies the formula (21).

$$
R_{i}=0.329 \omega_{e}+108
$$

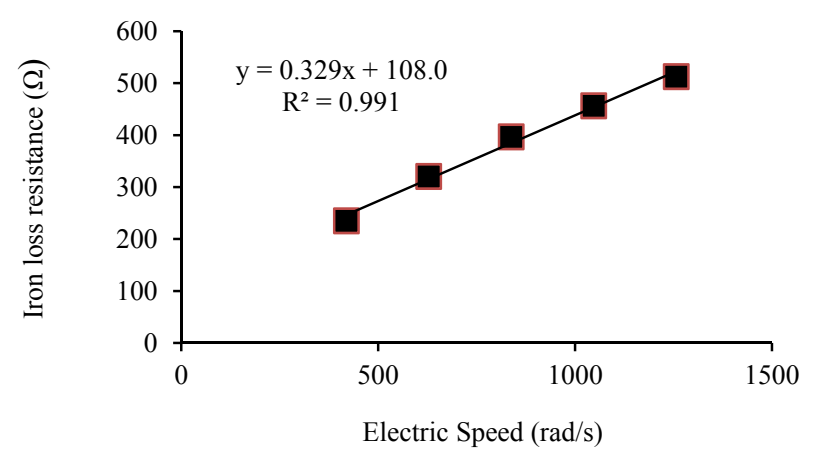

Figure 4 The curve of iron loss resistance and speed

\section{Analysis of Simulation Results}

The simulation is conducted at the electrical speed of $837.758 \mathrm{rad} / \mathrm{s}$. According to the formula (21), the iron loss equivalent resistance is $383.6 \Omega$ at this speed. The target torque steps from $30 \mathrm{NM}$ to $50 \mathrm{NM}$ at $0.02 \mathrm{~s}$. The loss minimization direct torque control and traditional direct torque control are simulated in the same situation respectively. The simulation results are shown in Figure 5, 6.

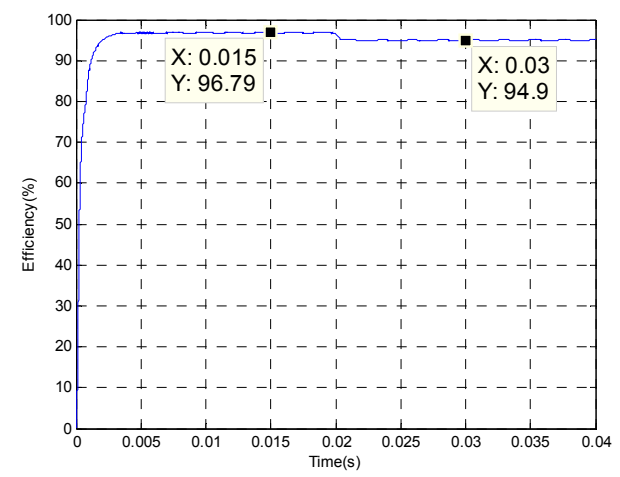

Figure 5 Efficiency of traditional direct torque control

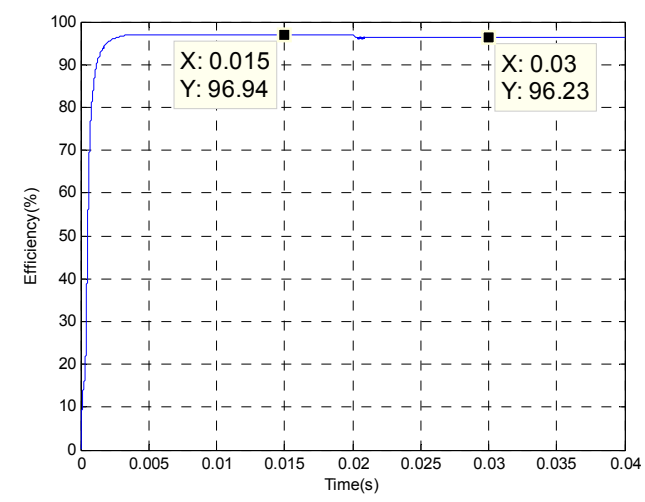

Figure 6 Efficiency of loss minimum direct torque control

Using traditional DTC method, the motor efficiency is $96.79 \%$ when the target torque is $30 \mathrm{NM}$ and the efficiency is $94.9 \%$ when the target torque is $50 \mathrm{NM}$. Using the method of loss minimization DTC, the motor efficiency is $96.94 \%$ when the target torque is $30 \mathrm{NM}$ and the efficiency is $96.23 \%$ when the target torque is $50 \mathrm{NM}$. It can be seen that the motor efficiency improves $0.15 \%$ when the target torque is $30 \mathrm{NM}$ and the efficiency improves $1.33 \%$ when the target torque is $50 \mathrm{NM}$ compared with the traditional DTC.

\section{Conclusions}

This paper proposes a loss minimum control method through adjusting the flux reference dynamically based on loss model. The relationship between equivalent iron loss resistance and speed is acquired by finite element simulation under different conditions. The iron loss resistance increases linearly with speed increasing. Using the proposed LMC method, motor efficiency is improved compared with traditional direct torque control. 


\section{Acknowledgements}

We would like to acknowledge the financial support by National Natural Science Foundation of China through Grant No.51204017 and the project No.KF14132 supported by the Science Fund of State Key Laboratory of Automotive Safety and Energy.

\section{References}

[1] Liu Wei-Gang. Study and Implementation of Direct Torque Control of PMSM Motor for Electric Vehicle Driving System. Chongqing: Chongqing University, 2011.

[2] Xu Yan-Ping. Research on Direct Torque Control Methods of Decreasing Torque Ripples for Permanent Magnet Synchronous Motors. Xian: Xi'an university of technology, 2008,8.

[3] Wang Jin. Core Loss Research and Design of Super Premium Efficiency PMSM. Shenyang: Shenyang University of Technology, 2009.

[4] Xu Jun-Feng, Feng Jiang-hua, Xu Jian-ping. Direct Torque Control of Permanent Magnet Synchronous Machine Considering Loss Model. Power Electronics, 39(2), pp.24-28, 2005.

[5] Xu Yan-Ping, ZHONG Yan-ru. Simulation of Minimum Loss Control for PMSM. Journal of System Simulation,19(22), pp.5283-5286, 2007.

[6] Chen Xu. Research on Loss Minimization Control Method of Permanent Magnet Synchronous Motor. Beijing: North China University of Technology, 2013.

[7] Kang Chang. Loss Minimization Control of Permanent Magnet Synchronous Machine For Electric Vehicle Applications. Montreal: Concordia University, 2013.

[8] A. Dittrich. Model Based Identification of The Iron Loss Resistance of An Induction Machine. In Proc. Power Electronics and Variable SpeedDrives, London, U.K., Sept. 1998, IEEE Conf. Pub. No. 456, pp. 500-503.

[9] Naomitsu Urasaki, TomonobuSenjyu, Katsumi Uezato. A Novel Calculation Method for Iron Loss Resistance Suitable in Modeling Permanent Magnet Synchronous Motors. IEEE transaction on energy conversion, 18(1), pp.41-47,2003.

[10] Francesco Fabio Quattrone. Dynamic Modelling of Losses in Electric Machines for Active Loss Control. Leibniz University Hannover. 2011, 6. 